\title{
Clinical study of the feasibility, complications, and cosmetic outcomes of immediate autologous fat grafting during breast-conserving surgery for early-stage breast cancer in China
}

\author{
Hongyuan Li ${ }^{1 \#}$, Yuanyuan Wang ${ }^{1 \#}$, Dejuan Yang ${ }^{1}$, Jean Yves Petit ${ }^{2}$, Guosheng Ren ${ }^{1}$ \\ ${ }^{1}$ Department of Endocrine and Breast Surgery, the First Affiliated Hospital of Chongqing Medical University, Chongqing, China; ${ }^{2}$ Division of Plastic \\ Surgery, European Institute of Oncology, Milano, Italy \\ Contributions: (I) Conception and design: JY Petit, H Li, G Ren; (II) Administrative support: H Li, G Ren; (III) Provision of study materials or \\ patients: H Li, Y Wang; (IV) Collection and assembly of data: Y Wang; (V) Data analysis and interpretation: Y Wang, D Yang; (VI) Manuscript \\ writing: All authors; (VII) Final approval of manuscript: All authors. \\ \#These authors contributed equally to this work. \\ Correspondence to: Guosheng Ren. Department of Endocrine and Breast Surgery, the First Affiliated Hospital of Chongqing Medical University, \\ Chongqing 400016, China. Email: rengs726@126.com; Jean Yves Petit. 2 rue Denfert Rochereau, 34200 Sète, France. Email: jean.petit@ieo.it.
}

\begin{abstract}
Background: The resection of tumors in small breasts or in areas such as the upper and inner parts of the breast may have disabling cosmetic results. Tumor resection reduces the volume of the breast and may result in asymmetry or distortion of the nipple-areola complex. Autologous fat transfer/grafting has been shown to be a reliable technique for improving these poor cosmetic results. This study aimed to evaluate the feasibility, complications, and cosmetic outcomes of immediate autologous fat grafting during breast-conserving surgery (BCS) in Chinese patients with early-stage breast cancer.

Methods: This retrospective study included 58 patients with early breast cancer treated by the same surgical team from October 2016 to May 2017. The patients were divided into two groups: BCS with lipofilling (experiment group, $n=30$ ) and BCS without lipofilling (control group, $n=28$ ). All patients received the recommended breast cancer treatment with complementary radiotherapy. The follow-up period after the completion of radiotherapy ranged from 36-44 months. The resected and grafted volumes, complications, esthetic results, patient satisfaction, and recurrence rate within 3 years were compared between the groups.

Results: The average resected and grafted volumes in the lipofilled group were 47 and $74 \mathrm{~mL}$, respectively, with only one seroma and no other complications. Regarding physician evaluation, BCS with lipofilling resulted in better cosmetic outcomes than BCS without lipofilling (33\% versus 15\%, respectively). Poor responses occurred in only $7 \%$ of patients with lipofilling, compared with $15 \%$ without lipofilling. Regarding patient self-evaluation, Breast-Q scores including patient satisfaction with their breasts and psychosocial well-being, were significantly higher in patients who received lipofilling compared with non-lipofilled patients. Regional recurrence occurred in one patient (case 21) (3.7\%) in the lipofilling group and systemic recurrence occurred in one patient (case 12) (3.8\%) in the control group.

Conclusions: Immediate autologous fat grafting is a promising, effective, and convenient technique for partial breast reconstruction after BCS, with potentially higher levels of patient and physician satisfaction compared with traditional BCS.
\end{abstract}

Trial Registration: Chinese Clinical Trial Registry ChiCTR-ONN-17010514. Registered 24 January 2017.

Keywords: Autologous fat grafting; breast cancer; breast-conserving surgery (BCS); breast reconstruction; lipofilling

Submitted Feb 28, 2021. Accepted for publication Jul 12, 2021.

doi: $10.21037 /$ gs-21-126

View this article at: https://dx.doi.org/10.21037/gs-21-126

(c) Gland Surgery. All rights reserved. 


\section{Introduction}

Breast-conserving surgery (BCS) with subsequent radiotherapy is equivalent to modified mastectomy in terms of its curative potential for early breast cancer, and provides a less-mutilated feeling for the patients. Good cosmetic results after surgery have an important impact on patient prognosis. A previous study demonstrated a direct correlation between a poor cosmetic outcome and poor body image, increased levels of anxiety and depression, and problems with sexuality and low self-esteem (1). However, the resection of tumors in small breasts or in certain areas, such as the upper and inner parts of the breast, may have disabling cosmetic results. Resection of the tumor reduces the volume of the breast and frequently results in asymmetry or distortion of the nippleareola complex. It is possible to avoid such deformities by reshaping the breast at the time of quadrantectomy, using various oncoplastic surgery (OPS) techniques (2). Fat transfer is a technique especially indicated for small or medium breasts and for tumors located in the upper part of the breast $(3,4)$. However, correction with fat grafting has to date usually been used to correct secondary deformities or sequelae after radiotherapy, and oncologic questions have been raised regarding the cancer risk associated with fat transfer in the vicinity of the tumor bed. Although several studies have compared the results of this technique with a control group, no randomized trials have been conducted and the safety of fat transfer in breast cancer patients remains inconclusive (5-7).

Concomitant lipofilling at the time of the BCS is not currently performed. Biazus et al. first published their experience of 20 cases treated with immediate fat grafting during BCS (5). They found no increase in local recurrence due to lipofilling, even after follow-up for 5 years (8). No results have been reported to date for Asian patients, however, this approach may be particularly suitable and practical for Asian women, who tend to have smaller breasts than their western peers. The current study aimed to evaluate the surgical feasibility of BCS plus lipofilling, and to analyze the complications and immediate results in a series of patients with breast cancer. We present the following article in accordance with the STROBE reporting checklist (available at https://dx.doi.org/10.21037/gs-21-126).

\section{Methods}

\section{General information}

This was a retrospective analysis of 58 patients with early breast cancer treated at the Department of Endocrine and Breast Surgery, the First Affiliated Hospital of Chongqing Medical University (Chongqing, China) from October 2016 to May 2017, including 30 patients treated with BCS + lipofilling (experimental group). The fat graft was injected in the breast tissue, muscle, and subcutaneous tissue around the resected area. The fat injection usually allowed natural closure of the defect. Twenty-eight patients of similar characteristics who underwent traditional BCS without lipofilling, performed by the same surgical team during the same time period, were identified as a control group. The study was conducted in accordance with the Declaration of Helsinki (as revised in 2013). The study was approved by the Institutional Ethics Committee of the First Affiliated Hospital of Chongqing Medical University and individual consent for this retrospective analysis was waived.

\section{Trial procedure}

All patients underwent high-resolution mammography, ultrasound examination, magnetic resonance imaging with contrast, and tumor biopsy before surgery. The eligibility criteria were as follows: stage I/II cancer; single tumor, $<4 \mathrm{~cm}$ in diameter and $>3 \mathrm{~cm}$ from the nipple; and appropriate tumor to breast volume ratio. Patients with metastasis, systemic diseases, or other cancers, or with absolute/relative contraindications were excluded. The BCS technique involved complete tumor removal with clear margins without skin resection, unless it was compromised by the skin-tumor proximity. A circumareolar incision was preferred in the upper part of the breast, while a radial incision was usually done in the inferior part of the breast. All patients, except those with ductal carcinoma in situ (DCIS), received chemotherapy 2 weeks after surgery. All patients received the recommended breast cancer treatment of complementary radiotherapy (conventional dose 50 Gy in 25 fractions to the chest wall and a boost of $10 \mathrm{~Gy}$ in 5 fractions to the tumor bed). Patients also received chemotherapy and hormone therapy based on their histopathological and immunohistochemical tumor characteristics. Patients were followed-up at 2 and 18 months after initial surgery and at 6 months after radiotherapy, using digital photographs of the breast and Breast-Q self-evaluation.

\section{Fat grafting technique}

The fat-grafting technique has been described by Coleman (9). 
In the current study, 28 of the 30 BCS + lipofilling cases received suction-assisted lipectomy and the other two received hand-held syringe aspiration. With the patient under general anesthesia and in the supine position, the thoracic area, abdomen, and thighs were prepared and draped. Tumescent anesthesia (1:1,000 epinephrine: saline) was initially developed to perform liposuction procedures. The fat graft was harvested from the abdomen using a manual aspiration cannula in two cases and using a liposuction machine (KYZ-2; Beijing KYYS Medical Treatment Technology, Beijing, China) in the other 28 cases. The fat was removed from the subcutaneous tissue by liposuction with a $2.5 \mathrm{~mm}$ cannula, usually from the abdomen or from other donor sites according to the patient's morphology. The fat was then centrifuged at 1,000 rpm for 2 minutes to remove oil and blood fractions. The purified fat was then transferred to $10 \mathrm{~mL}$ syringes and injected using a blunt $2.0 \mathrm{~mm}$ needle. Injection proceeded during the withdrawal movement to avoid fat emboli with adipocytes in small vessels. Injections were carried out all around the tumor bed, within the breast, and in the pectoralis muscle. Accumulation of fat tissue inside the tumor bed was avoided because of the risk of necrosis of the fat bolus due to poor vascularization. Closure of the tumor bed sometimes required a concomitant OPS technique using a local glandular flap. A small glandular flap was prepared by subcutaneous dissection, allowing partial reduction of the defect, which was completed by fat injection to restore the natural shape of the breast. Because the grafted fat was frequently reabsorbed, overcorrection was recommended by injecting 1.5-2-fold the volume of the specimen, which reduced slowly after 2-3 months.

\section{Panel evaluation}

The images were evaluated by a three-member panel (one experienced breast surgeon and two laymen). None of the panel members had performed surgery on the patients, and the observers were blinded to the patient information and study arm. Breast shape, volume, deformity, surgical scarring, nipple position, skin alterations, and overall cosmetic outcome were all recorded. And scored using the 4-point Likert scale as excellent, good, fair, or poor. "Excellent" indicated identical to the untreated breast and "poor" indicated a marked difference with the untreated breast (10).

\section{Cosmetic self-evaluation}

Breast-Q is a validated patient reported outcome tool measuring breast-related satisfaction and quality of life (QOL). The satisfaction domains include satisfaction with breasts (appearance of the breast and fit of bras and clothing), outcome (patient's feeling about the surgical outcome) and care; the QOL domains include psychosocial (confidence in a social setting, emotional health, selfconfidence and attractiveness), physical (chest and back pains), and sexual well-being. In this study, we focused on the breast satisfaction and psychosocial well-being modules, with higher scores indicating better satisfaction or QOL.

\section{Statistical analysis}

Statistical analyses were carried out using GraphPad Prism 6.0c software. Categorical variables were compared by $\chi^{2}$ or Fisher's exact tests and means of continuous variable were compared by estimation of two-tailed $\mathrm{P}$ values using Student's or Mann-Whitney tests.

\section{Results}

A total of 58 patients were included in the study, including 30 treated with BCS + lipofilling and 28 treated with traditional BCS. The $30 \mathrm{BCS}+$ lipofilling patients included 26 cases of invasive breast cancer, two DCIS, one mucinous tumor, and one with medullary features. The BCS group included 23 cases of invasive breast cancer, four DCIS, and one with medullary features. The patients' characteristics are listed in Table 1. The cases and controls showed similar characteristics. Pathological assessment of the primary tumor (pT) was pT1 and pT2 for all patients. The median ages at surgery were 44.6 years (range, $30-63$ years) in the lipofilled group and 45.3 years (26-61 years) in the nonlipofilled group. The mean body mass indexes (BMIs) were 22.9 and $22.6 \mathrm{~kg} / \mathrm{m}^{2}$ and the median tumor diameters were 21 and $22 \mathrm{~mm}$ in the lipofilled and non-lipofilled groups, respectively. Three patients (cases 14, 21 and 28) in the lipofilled group and two (cases 12 and 15) in the control group refused follow-up.

Seven patients in the lipofilled group and five in the non-lipofilled group had axillary lymph nodes metastasis. Frozen sections were obtained to increase the chance of free margins before lipofilling. No patient with tumorinvolved margins in either group underwent mastectomy. Two tumors in the lipofilled group had lymphovascular invasion and two had extensive intraductal components (Tables 2 and 3). Fifteen patients (50\%) had tumors located 
Table 1 Patient characteristics (matching variables)

\begin{tabular}{|c|c|c|c|}
\hline Characteristics & BCS + lipofilling $(n=30)$ & $\operatorname{BCS}(n=28)$ & $P$ value \\
\hline BMI $\left(\mathrm{kg} / \mathrm{m}^{2}\right)$ & $22.87 \pm 1.85$ & $22.57 \pm 2.43$ & 0.654 \\
\hline Tumor size (mm) & $21.17 \pm 6.38$ & $21.96 \pm 7.48$ & 0.720 \\
\hline Positive nodes & & & 0.468 \\
\hline 1 & $2(6.7 \%)$ & $4(13.3 \%)$ & \\
\hline 2 & $3(10 \%)$ & $1(3.6 \%)$ & \\
\hline$\geq 3$ & $2(6.7 \%)$ & 0 & \\
\hline Estrogen receptor & & & 0.159 \\
\hline Progesterone receptor & & & 0.574 \\
\hline Negative & $14(46.7 \%)$ & 11 (39.3\%) & \\
\hline Positive & $16(53.3 \%)$ & $17(60.7 \%)$ & \\
\hline Ki-67 & & & 0.633 \\
\hline$<20$ & $11(36.7 \%)$ & 12 (42.9\%) & \\
\hline$\geq 20$ & $19(63.3 \%)$ & $16(57.1 \%)$ & \\
\hline HER-2 & & & 0.398 \\
\hline Overexpressed & 7 (23.3\%) & $3(10.7 \%)$ & \\
\hline
\end{tabular}

$\mathrm{BCS}$, breast-conserving surgery; BMI, body mass index.

in the upper-outer quadrant, $13(43.3 \%)$ were in the inner quadrants and the junction of the upper quadrants, 1 $(3.3 \%)$ was in the lower-outer quadrant, and $1(3.3 \%)$ was in the lower-inner quadrant. The average resected volume was $47 \mathrm{~mL}$ and the average grafted volume was $74 \mathrm{~mL}$ (Tables 4 and 5). Only one patient in the control group had an extensive intraductal component, $16(57 \%)$ had tumors in the upper-outer quadrant, $6(21 \%)$ in the inner quadrants and junction of the upper quadrants, $3(11 \%)$ in the lowerouter quadrant, and $3(11 \%)$ in the lower-inner quadrant (Tables 4 and 5).

The follow-up period after the completion of radiotherapy ranged from 36-44 months. One patient in the lipofilled group had a seroma, but no other complications, such as cyst formation, fat necrosis, infection, granuloma, and pneumothorax, were observed. There were no complications in any of the donor sites (Tables 4 and 5). The length of hospital stay was similar in both groups (2 days after surgery).

The esthetic results were optimal, with significant breast symmetry according to both the surgeons and patients. The esthetic scores were good or excellent in most cases (Figure 1A-1C). BCS with lipofilling resulted in better cosmetic outcomes than BCS without lipofilling (33\% versus $15 \%$, respectively). Only $7 \%$ of responses in the lipofilling group were poor, compared with $23 \%$ without lipofilling (Table 6). Regarding patient selfevaluation, Breast-Q scores showed significant greater with very satisfaction in patients who had received lipofilling compare with non-lipofilled patients in terms of appearance in the mirror clothed (50\% lipofilled $v s$. $11.5 \%$ non-lipofilled) and unclothed (42.3\% vs. $15 \%)$, size of breasts ( $53 \%$ vs. $31 \%)$, wearing fitted clothing $(68 \%$ 
Table 2 Summary of cases: BCS + lipofilling (experiment group)

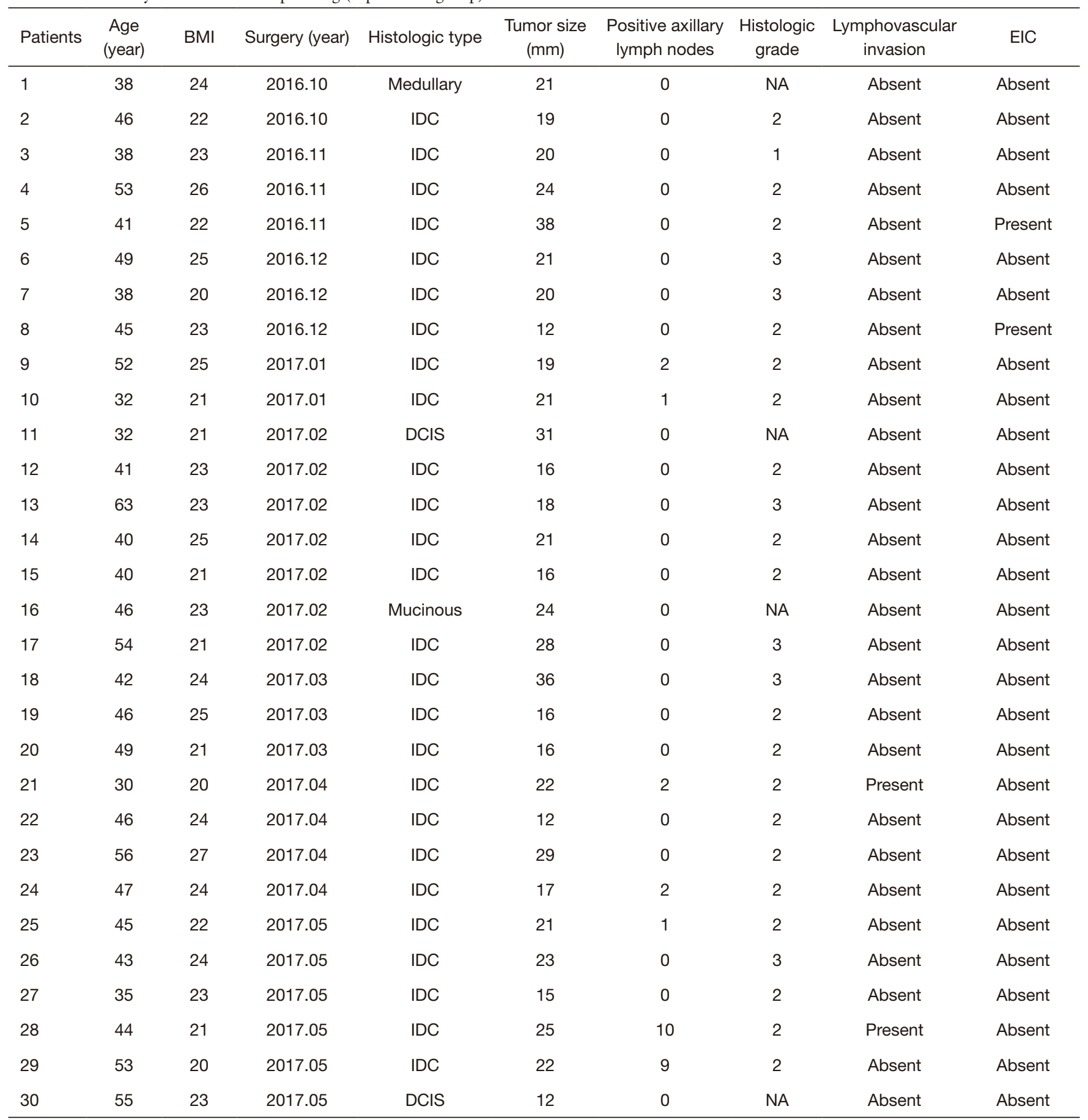

BCS, breast-conserving surgery; BMI, body mass index; EIC, extensive intraductal component; IDC, invasive ductal carcinoma; DCIS, ductal carcinoma in situ; NA, not available.

vs. $38 \%)$, smoothness of operated breast ( $57 \%$ vs. $20 \%$ ), and shape of breasts in bra (50\% vs. 23\%) (Figure 2). Even after radiotherapy, most cases maintained optimal esthetic results. Psychosocial well-being scores were also significantly higher in patients who received lipofilling $(\mathrm{P}<0.0001)$ (Figure 3). Patient evaluation and data 
Table 3 Summary of cases: BCS (control group)

\begin{tabular}{|c|c|c|c|c|c|c|c|c|c|}
\hline Patients & $\begin{array}{l}\text { Age } \\
\text { (year) }\end{array}$ & BMI & Surgery (year) & Histologic type & $\begin{array}{c}\text { Tumor size } \\
\text { (mm) }\end{array}$ & $\begin{array}{l}\text { Positive axillary } \\
\text { lymph nodes }\end{array}$ & $\begin{array}{l}\text { Histologic } \\
\text { grade }\end{array}$ & $\begin{array}{l}\text { Lymphovascular } \\
\text { invasion }\end{array}$ & EIC \\
\hline 1 & 48 & 21 & 2016.09 & IDC & 11 & 0 & 2 & Absent & Absent \\
\hline 3 & 26 & 24 & 2016.09 & IDC & 30 & 0 & 3 & Absent & Absent \\
\hline 6 & 28 & 25 & 2016.10 & IDC & 33 & 0 & 2 & Absent & Absent \\
\hline 7 & 35 & 22 & 2016.10 & IDC & 22 & 1 & 2 & Absent & Absent \\
\hline 8 & 54 & 26 & 2016.10 & DCIS & 17 & 0 & NA & Absent & Absent \\
\hline 12 & 52 & 24 & 2016.11 & Medullary & 30 & 1 & NA & Absent & Absent \\
\hline 13 & 42 & 21 & 2016.12 & IDC & 17 & 0 & 3 & Absent & Absent \\
\hline 14 & 48 & 21 & 2016.12 & IDC & 15 & 1 & 3 & Absent & Absent \\
\hline 15 & 43 & 26 & 2017.01 & IDC & 19 & 0 & 2 & Absent & Absent \\
\hline 16 & 46 & 25 & 2017.02 & DCIS & 30 & 0 & NA & Absent & Absent \\
\hline 17 & 46 & 22 & 2017.03 & DCIS & 28 & 0 & NA & Absent & Absent \\
\hline 18 & 44 & 23 & 2017.03 & IDC & 21 & 0 & 2 & Absent & Absent \\
\hline 24 & 48 & 25 & 2017.05 & IDC & 12 & 0 & 1 & Absent & Absent \\
\hline 25 & 61 & 26 & 2017.05 & IDC & 24 & 0 & 2 & Absent & Absent \\
\hline 26 & 45 & 20 & 2017.05 & DCIS & 35 & 0 & NA & Absent & Absent \\
\hline 27 & 42 & 24 & 2017.05 & IDC & 16 & 0 & 2 & Absent & Absent \\
\hline 28 & 48 & 19 & 2017.05 & IDC & 21 & 0 & 3 & Absent & Absent \\
\hline
\end{tabular}

BCS, breast-conserving surgery; BMI, body mass index; EIC, extensive intraductal component; IDC, invasive ductal carcinoma; DCIS, ductal carcinoma in situ; NA, not available.

collection continues to be performed regularly.

Regional recurrence occurred one patient (case 21) $(3.7 \%)$ in the lipofilling group and systemic recurrence occurred in one patient (case 12$)(3.8 \%)$ in the control group.

\section{Discussion}

Breast cancer is the most widespread malignant tumor in women worldwide, accounting for approximately $17.1 \%$ of all female malignant tumors in China. A total of 278,800 women in China were diagnosed with breast cancer in 2013 (11). 
Table 4 Summary of surgery: BCS + lipofilling (experiment group)

\begin{tabular}{|c|c|c|c|c|c|c|c|}
\hline Patients & $\begin{array}{l}\text { Follow-up } \\
\text { (months) }\end{array}$ & Primary tumor site & Size of breast & Volume resected (g) & Volume grafted (g) & Esthetic results & Complications \\
\hline 1 & 43 & $\mathrm{R}, \cup O Q$ & $\mathrm{C}$ & 46 & 65 & Excellent & - \\
\hline 3 & 42 & $\mathrm{R}, \mathrm{UIQ}$ & $B$ & 37 & 45 & Fair & - \\
\hline 4 & 42 & $\mathrm{R}, \mathrm{UOQ}$ & $\mathrm{C}$ & 85 & 130 & Excellent & - \\
\hline 6 & 41 & $\mathrm{R}, \mathrm{\cup OQ}$ & $B$ & 32 & 78 & Good & - \\
\hline 7 & 41 & L, UIQ & A & 38 & 75 & Excellent & - \\
\hline 8 & 41 & L, JUQ & $\mathrm{B}$ & 16 & 45 & Excellent & - \\
\hline 12 & 39 & L, UIQ & $\mathrm{D}$ & 43 & 50 & Good & - \\
\hline 13 & 39 & $\mathrm{R}, \mathrm{UIQ}$ & B & 18 & 40 & Excellent & - \\
\hline 14 & 39 & L, UOQ & C & 63 & 100 & - & - \\
\hline 15 & 39 & L, UIQ & C & 43 & 53 & Good & - \\
\hline 16 & 39 & L, UOQ & B & 35 & 74 & Excellent & - \\
\hline 17 & 39 & L, UOQ & B & 22 & 60 & Excellent & - \\
\hline 18 & 38 & L, UOQ & B & 30 & 60 & Good & - \\
\hline 24 & 37 & R, JUQ & B & 39 & 50 & Fair & Seroma \\
\hline 25 & 37 & $\mathrm{R}, \mathrm{LOQ}$ & $\mathrm{C}$ & 83 & 110 & Fair & - \\
\hline 26 & 37 & L, UIQ & C & 52 & 80 & Excellent & - \\
\hline 27 & 36 & L, LIQ & $\mathrm{C}$ & 34 & 75 & Good & - \\
\hline 28 & 36 & L, UOQ & B & 40 & 110 & - & - \\
\hline 29 & 36 & R, JOQ & B & 80 & 120 & Good & - \\
\hline 30 & 39 & R, JUQ & B & 30 & 60 & Excellent & - \\
\hline
\end{tabular}

$A, B, C, D$, according to the bra size; BCS, breast-conserving surgery; JOQ, junction of the outer quadrants; JUQ, junction of the upper quadrants; LOQ, lower-outer quadrant; LIQ, lower-inner quadrant; UOQ, upper-outer quadrant; UIQ, upper-inner quadrant.

Approximately $60 \%$ of patients with breast cancer are diagnosed at an early stage, because of the expansion of mammographic screening. BCS is oncologically and surgically safe, with long-term survival comparable to that of total mastectomy. Although $>60 \%$ of patients with early-stage breast cancer in the USA undergo BCS, the 
Table 5 Summary of surgery: BCS (control group)

\begin{tabular}{|c|c|c|c|c|c|c|}
\hline Patients & Follow-up (months) & Primary tumor site & Size of breast & Tumor size (mm) & Esthetic results & Complications \\
\hline 1 & 44 & $R, \cup O Q$ & B & 11 & Good & - \\
\hline 2 & 44 & L, LIQ & C & 10 & Good & - \\
\hline 3 & 44 & $\mathrm{R}, \cup O Q$ & B & 30 & Poor & - \\
\hline 4 & 44 & L, JOQ & B & 29 & Poor & - \\
\hline 5 & 44 & L, UIQ & C & 28 & Fair & - \\
\hline 6 & 43 & L, JOQ & C & 33 & Poor & - \\
\hline 7 & 43 & L, UIQ & C & 22 & Good & - \\
\hline 8 & 44 & L, UIQ & A & 17 & Good & - \\
\hline 9 & 43 & $\mathrm{R}, \mathrm{UOQ}$ & B & 34 & Fair & - \\
\hline 10 & 42 & L, UOQ & B & 18 & Excellent & - \\
\hline 11 & 42 & $\mathrm{~L}, \mathrm{UIQ}$ & C & 19 & Excellent & - \\
\hline 12 & 42 & L, UOQ & B & 30 & - & - \\
\hline 13 & 41 & $\mathrm{R}, \mathrm{JUQ}$ & B & 17 & Fair & - \\
\hline 14 & 41 & L, LOQ & A & 15 & Good & - \\
\hline 15 & 40 & $\mathrm{R}, \mathrm{UOQ}$ & B & 19 & - & - \\
\hline 16 & 43 & L, UOQ & C & 30 & Good & - \\
\hline 17 & 43 & L, JIQ & A & 28 & Fair & - \\
\hline 18 & 40 & L, UOQ & B & 21 & Excellent & - \\
\hline 19 & 39 & L, LIQ & B & 14 & Poor & - \\
\hline 20 & 39 & L, JUQ & C & 21 & Good & - \\
\hline 21 & 39 & L, JUQ & A & 11 & Good & - \\
\hline 22 & 38 & $\mathrm{R}, \mathrm{LIQ}$ & C & 28 & Poor & - \\
\hline 23 & 38 & L, UIQ & B & 22 & Excellent & - \\
\hline 24 & 38 & $\mathrm{R}, \mathrm{UOQ}$ & B & 12 & Fair & - \\
\hline 25 & 38 & L, UOQ & C & 24 & Good & - \\
\hline 26 & 40 & L, UOQ & B & 35 & Poor & - \\
\hline 27 & 38 & $\mathrm{R}, \mathrm{LOQ}$ & B & 16 & Good & - \\
\hline 28 & 38 & L, LOQ & B & 21 & Good & - \\
\hline
\end{tabular}

$A, B, C, D$, according to the bra size; BCS, breast-conserving surgery; JOQ, junction of the outer quadrants; JUQ, junction of the upper quadrants; LOQ, lower-outer quadrant; LIQ, lower-inner quadrant; UOQ, upper-outer quadrant; UIQ, upper-inner quadrant.

procedure is much less common in China, with a nationwide rate of only $11.2 \%$ (12). However, economic and societal developments and an improved understanding of BCS mean that increasing numbers of patients are like to choose this surgery in future. However, the esthetic outcomes of BCS in terms of breast shape and symmetry are not always optimal, and almost $25-30 \%$ of women are not satisfied after BCS (13). A combination of OPS and BCS has been developed to overcome these shortcomings (14). The two main factors affecting the esthetic results are tumor location and tumorto-breast volume. The technique of fat transfer is especially indicated for small or medium-sized breasts and for tumors 

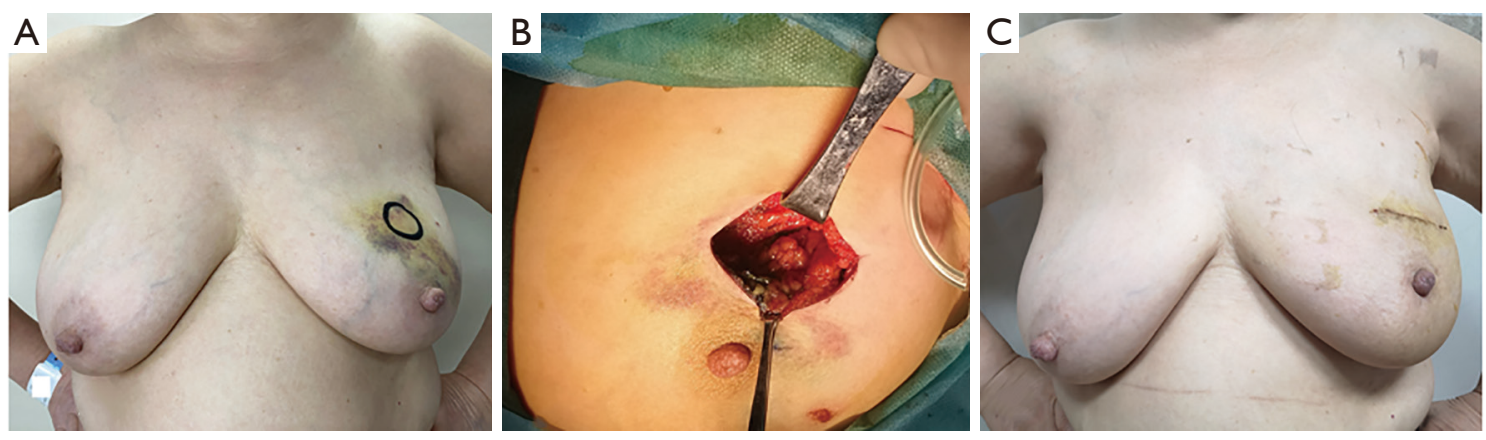

Figure 1 Preoperative, intraoperative, and postoperative views of lipofilling procedure. (A,B) Preoperative view of a 55-year-old woman with a tumor in the upper quadrant of the left breast. The resected volume was $53 \mathrm{~mL}$ and the injected fat grafting volume was $80 \mathrm{~mL}$ in a single session; (C) postoperative view 1 month after surgery.

Table 6 Patient surgical characteristics

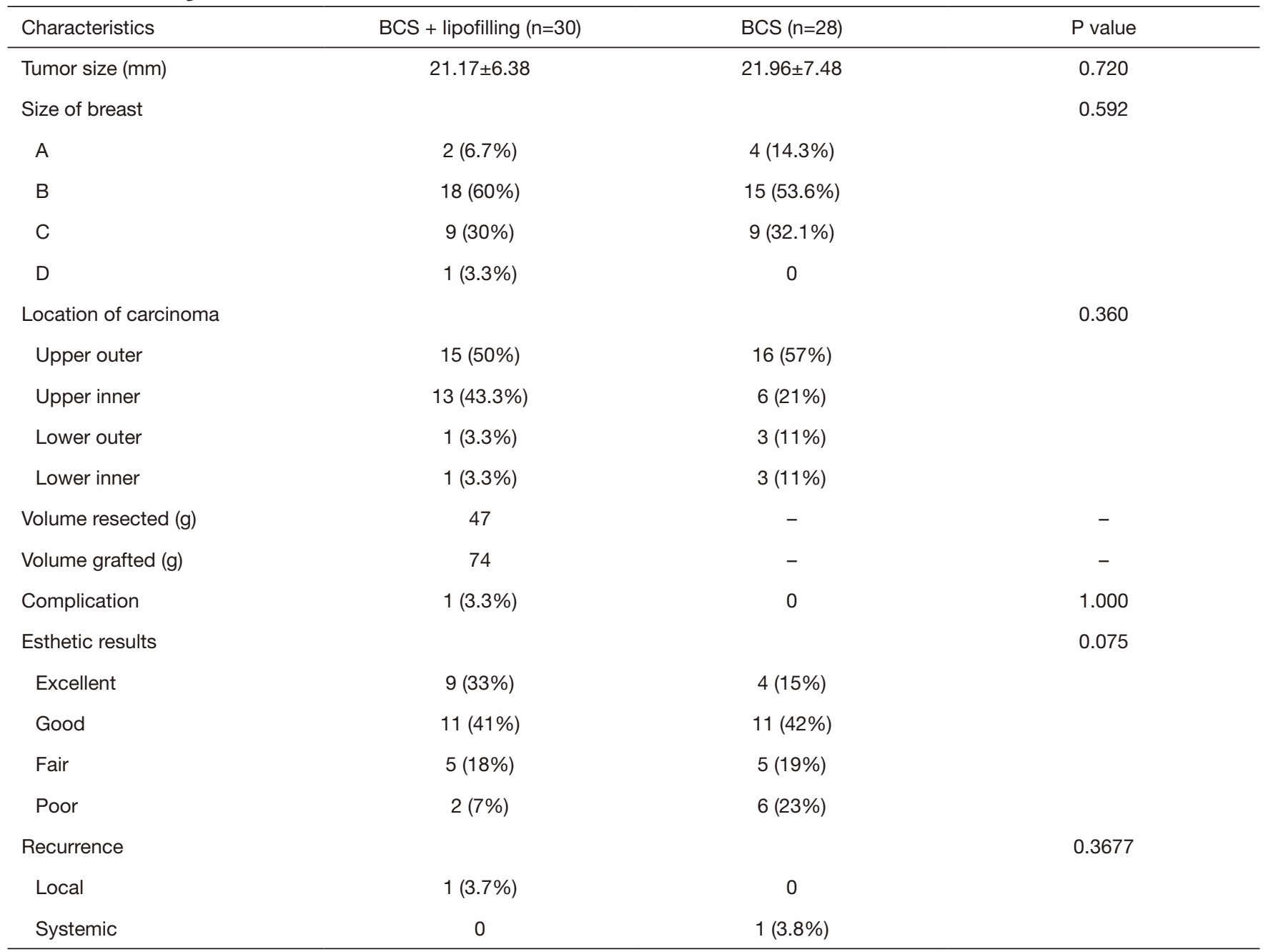

$A, B, C, D$, according to the bra size; BCS, breast-conserving surgery. 

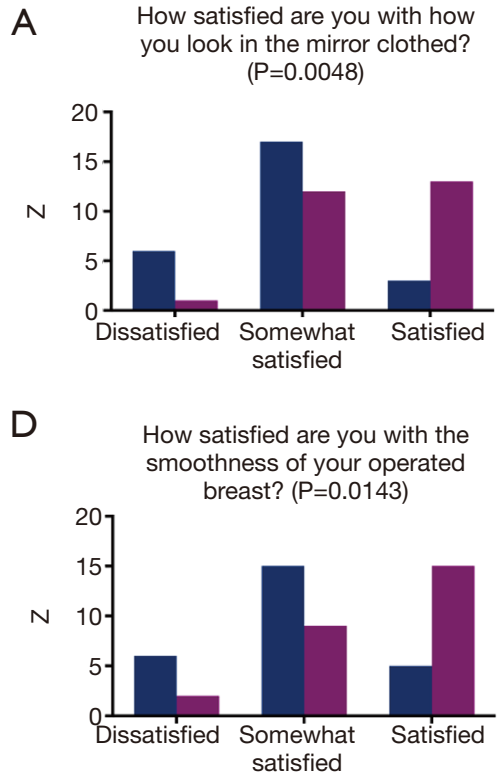

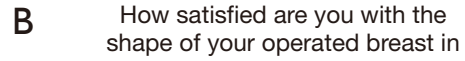
bra? $(P=0.1197)$

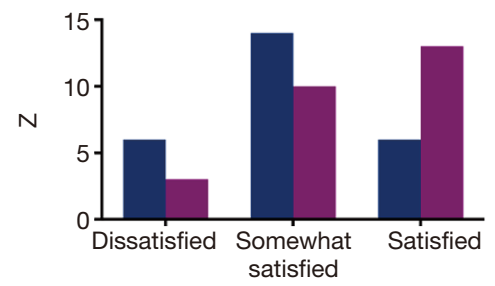

E How equal in size your breasts are? $(\mathrm{P}=0.1967)$

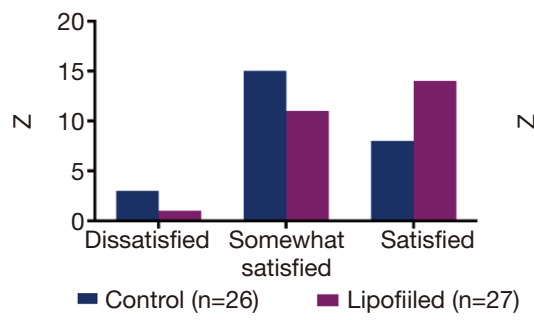

C Able to wear fitted clothing? $(\mathrm{P}=0.0806)$

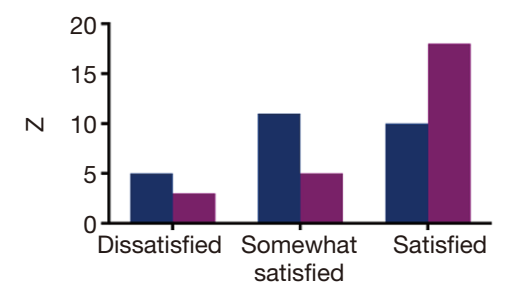

$\mathrm{F}$

How satisfied are you with how you look in the mirror unclothed? $(P=0.0071)$

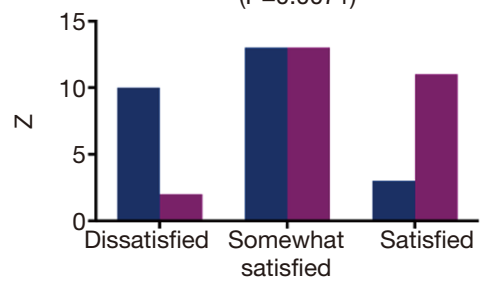

Figure 2 Patients-reported satisfaction with physical appearance. (A) How satisfied are you with how you look in the mirror clothed? (B) How satisfied are you with the shape of your operated breast in bra? (C) Able to wear fitted clothing? (D) How satisfied are you with the smoothness of your operated breast? (E) How equal in size your breasts are? (F) How satisfied are you with how you look in the mirror unclothed?

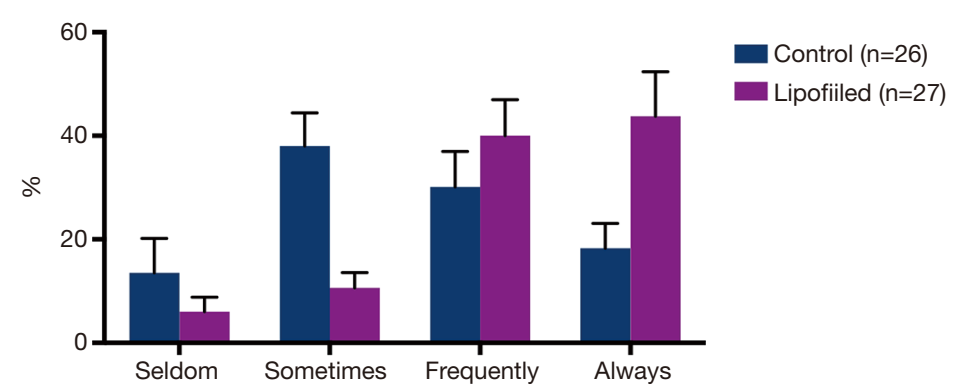

Figure 3 Distribution of reported psychosocial well-belling (all domains-confidence in a social setting, emotional health, self-confidence and attractiveness) in lipofilled and non-lipofilled patients (errors bars are $\pm 5 \%$ of total percentage).

located in the upper part of the breast. In light of the generally smaller breasts of Chinese women, this technique represents a simple and effective procedure, especially when accompanied by immediate fat grafting, to avoid the economic and surgical burdens caused by secondary surgery.

Several clinical and experimental studies have evaluated the safety of fat grafting for breast cancer treatment. We previously demonstrated that tumor-surrounding adipocytes stimulated the invasive behavior of breast cancer cells both in vitro and in mouse models $(15,16)$. However, clinical studies found no increased cancer risk related to fat transfer, except for one matched-control study that showed an increased risk of local recurrences in patients with in situ breast cancer (17). However, the study population was small and the follow-up time was short, which may have decreased the reliability of the results.

Biazus et al. was the first to publish his experience of immediate fat grafting for BCS in 20 patients (5). They subsequently found no increase in local recurrence due to lipofilling, even after 5 years of follow-up. These findings suggest that immediate reconstruction by lipofilling is oncologically safe (6). Another matched-control study using 
the same protocol as the IEO study also found no increase in the number of local recurrences or metastases following lipofilling (18). Finally, the latest IEO study comparing 324 BCS with fat transfer with 324 control procedures also reassuringly showed no increase in local recurrence or metastasis in the study group (19). Although these studies were not randomized, their well-matched control groups suggested that the procedure was safe from an oncological point of view.

China is a latecomer in implementing this approach, with few relevant reports to date. Evidence from welldesigned clinical studies is therefore needed to determine the suitability and safety of immediate lipofilling for breast cancer patients in China. The current study explored the technical feasibility of autologous fat grafting for immediate partial breast reconstruction during conservative surgery for breast cancer in a prospective series of 30 patients. The esthetic results were optimal, with both surgeons and patients reporting significant breast symmetry. None of the 30 patients developed complications such as cyst formation, fat necrosis, infection, granuloma, or pneumothorax, and there was only one case of seroma requiring drainage and leading to total fat resorption.

Our series showed that the immediate fat transfer technique was performed in most patients with a low BMI and small breasts, and for tumors located in the upper-inner quadrant, which is the most difficult area to reconstruct using OPS techniques. In one patient with a small tumor (case 8 ), the decision to use lipofilling was taken by the surgeon during surgery because of a defect remaining after simple closure. The volume of fat injected was greater than the resected specimen volume to compensate for normal resorption during the immediate follow-up period. The addition of lipofilling did not increase the length of the hospital stay. Only one case of regional recurrence was observed among the 30 patients treated with BCS + lipofilling.

Our pilot studies have shown the feasibility of performing immediate fat transfer at the same time as conservative treatment. This approach can be learnt quickly by breast surgeons, only adds approximately $20 \mathrm{~min}$ to the operation time, and provides high degrees of patient and physician satisfaction with a low surgical complication risk. This technique may thus replace more complex procedures for breast reconstruction after BCS. And is likely to find broad and quick clinical applications in China and Asia.

The potential limitations of this study included the small sample size (30 lipofilled and 28 non-lipofilled patients) and the limited follow-up period. Additionally, the retrospective design of this study could include bias, and the study did not use a perfectly matched cohort. Lastly, not all patients were willing to take the Breast-Q survey. We are currently conducting a prospective randomized trial with a longer follow-up time and larger sample size, and the results will be reported in due course.

\section{Conclusions}

The unsatisfactory cosmetic results following BCS have sharply increased the popularity of OPS. Immediate autologous fat transfer/grafting has advantages over other OPS techniques in patients with small breasts or tumors located in the upper and inner part of the breast. In light of the generally smaller breasts in Chinese women, this technique avoids the economic and surgical burdens associated with secondary surgery. The current results suggested that BCS with lipofilling could increase patient and physician satisfaction compared with BCS for Chinese patients with early-stage breast cancer. Based on these promising results, evidence from well-designed clinical studies is needed to confirm the oncological safety of immediate lipofilling for Chinese patients with early-stage breast cancer.

\section{Acknowledgments}

We thank International Science Editing (http://www. internationalscienceediting.com) for editing this manuscript. Funding: None.

\section{Footnote}

Reporting Checklist: The authors have completed the STROBE reporting checklist. Available at https://dx.doi. org/10.21037/gs-21-126

Data Sharing Statement: Available at https://dx.doi. org/10.21037/gs-21-126

Peer Review File: Available at https://dx.doi.org/10.21037/ gs-21-126

Conflicts of Interest: All authors have completed the ICMJE uniform disclosure form (available at https://dx.doi. org/10.21037/gs-21-126). The authors have no conflicts of interest to declare. 
Ethical Statement: The authors are accountable for all aspects of the work in ensuring that questions related to the accuracy or integrity of any part of the work are appropriately investigated and resolved. The study was conducted in accordance with the Declaration of Helsinki (as revised in 2013). The study was approved by the Institutional Ethics Committee of the First Affiliated Hospital of Chongqing Medical University, and was registered at the Chinese Clinical Trial Registry (ChiCTRONN-17010514). Individual consent for this retrospective analysis was waived.

Open Access Statement: This is an Open Access article distributed in accordance with the Creative Commons Attribution-NonCommercial-NoDerivs 4.0 International License (CC BY-NC-ND 4.0), which permits the noncommercial replication and distribution of the article with the strict proviso that no changes or edits are made and the original work is properly cited (including links to both the formal publication through the relevant DOI and the license). See: https://creativecommons.org/licenses/by-nc-nd/4.0/.

\section{References}

1. Al-Ghazal SK, Fallowfield L, Blamey RW. Comparison of psychological aspects and patient satisfaction following breast conserving surgery, simple mastectomy and breast reconstruction. Eur J Cancer 2000;36:1938-43.

2. Losken A, Hart AM, Chatterjee A. Updated Evidence on the Oncoplastic Approach to Breast Conservation Therapy. Plast Reconstr Surg 2017;140:14S-22S.

3. Delay E, Gosset J, Toussoun G, et al. Efficacy of lipomodelling for the management of sequelae of breast cancer conservative treatment. Ann Chir Plast Esthet 2008;53:153-68.

4. Illouz YG. The fat cell "graft": a new technique to fill depressions. Plast Reconstr Surg 1986;78:122-3.

5. Biazus JV, Falcão CC, Parizotto AC, et al. Immediate Reconstruction with Autologous fat Transfer Following Breast-Conserving Surgery. Breast J 2015;21:268-75.

6. Stumpf CC, Biazus JV, Zucatto FSÂE, et al. Immediate reconstruction with autologous fat grafting: influence in breast cancerregional recurrence. Rev Col Bras Cir 2017;44:179-86.

7. Khan LR, Raine CR, Dixon JM. Immediate lipofilling in breast conserving surgery. Eur J Surg Oncol
2017;43:1402-8.

8. Stumpf CC, Zucatto ÂE, Cavalheiro JAC, et al. Oncologic safety of immediate autologous fat grafting for reconstruction in breast-conserving surgery. Breast Cancer Res Treat 2020;180:301-9.

9. Coleman SR. Facial recontouring with lipostructure. Clin Plast Surg 1997;24:347-67.

10. Harris JR, Levene MB, Svensson G, et al. Analysis of cosmetic results following primary radiation therapy for stages I and II carcinoma of the breast. Int J Radiat Oncol Biol Phys 1979;5:257-61.

11. Chen W, Zheng R, Zhang S, et al. Cancer incidence and mortality in China, 2013. Cancer Lett 2017;401:63-71.

12. Jonczyk MM, Jean J, Graham R, et al. Surgical trends in breast cancer: a rise in novel operative treatment options over a 12 year analysis. Breast Cancer Res Treat 2019;173:267-74.

13. Wang HT, Barone CM, Steigelman MB, et al. Aesthetic outcomes in breast conservation therapy. Aesthet Surg J 2008;28:165-70.

14. Macmillan RD, McCulley SJ. Oncoplastic Breast Surgery: What, When and for Whom? Curr Breast Cancer Rep 2016;8:112-7.

15. Wang YY, Attané C, Milhas D, et al. Mammary adipocytes stimulate breast cancer invasion through metabolic remodeling of tumor cells. JCI Insight 2017;2:e87489.

16. Yang D, Li Y, Xing L, et al. Utilization of adipocytederived lipids and enhanced intracellular trafficking of fatty acids contribute to breast cancer progression. Cell Commun Signal 2018;16:32.

17. Petit JY, Botteri E, Lohsiriwat V, et al. Locoregional recurrence risk after lipofilling in breast cancer patients. Ann Oncol 2012;23:582-8.

18. Gale KL, Rakha EA, Ball G, et al. A case-controlled study of the oncologic safety of fat grafting. Plast Reconstr Surg 2015;135:1263-75.

19. Petit JY, Maisonneuve P, Rotmensz N, et al. Fat Grafting after Invasive Breast Cancer: A Matched Case-Control Study. Plast Reconstr Surg 2017;139:1292-6.

Cite this article as: Li H, Wang Y, Yang D, Petit JY, Ren G. Clinical study of the feasibility, complications, and cosmetic outcomes of immediate autologous fat grafting during breastconserving surgery for early-stage breast cancer in China. Gland Surg 2021;10(8):2386-2397. doi: 10.21037/gs-21-126 